\title{
PV/T Systems: Effect of Both Storage Features and Load Configuration
}

\author{
Laura Cirrincione $^{2}$, Cristina Malara ${ }^{1}$, Concettina Marino ${ }^{1}$, Antonino Nucara ${ }^{1}$, Giorgia Peri ${ }^{2}$, Matilde \\ Pietrafesa $^{1}$ \\ ${ }^{1}$ Department of Civil, Energy, Environmental and Material Engineering (DICEAM), \\ "Mediterranea" University of Reggio Calabria, Reggio Calabria, Italy \\ ${ }^{2}$ Department of Engineering (DIING), University of Palermo, Italy
}

\begin{abstract}
$\mathrm{PV} / \mathrm{T}$ panels are innovative systems increasingly used in the building sector. Their energy production and overall efficiency depend on several factors related to the shares of electrical and thermal loads and to the working temperature of the operating fluid. Therefore, an optimal configuration should be found. In this work, a parametric analysis was performed to provide a contribute on this issue. The conclusive indications can be exploited by designers and researchers, to maximize the efficiency of the systems in relation to configurations and to both electrical and thermal loads.
\end{abstract}

To this purpose a simulation model was designed and implemented in a spreadsheet, using Visual Basic ${ }^{\mathrm{TM}}$ functions.

\section{Introdu ction}

Nowadays, the energy policy of any country tries to address a plurality of issues like energy security, economic growth and environment protection (Michael et al., 2015).

Considering these points of view, Renewable Energy Sources, appear to be a valid solution able to flank or, in particular situations, to entirely substitute fossil fuels. Actually, the renewable energy sources are used to supply only $14 \%$ of the world's total energy consumption (Panwar, Kaushik, and Kothari, 2011), but their role is likely bound to increase because of the rising fossil fuel prices, global warming and planetary pollution problems which need to be addressed.

Solar energy, among all other available energy resources may be considered as the most abundant, inexhaustible and cleanest. As a consequence, the installed area of solar technologies around the world is progressively increasing (International Energy Agency (IEA), 2018) with a pace that give us an idea about the unlimited potential available in solar energy.

Many researchers around the world are developing the system based on solar energy (Joshi and Dhoble, 2018) . The major applications of solar energy can be classified into two categories: solar thermal system, which converts solar energy into thermal energy, and photovoltaic (PV) system, which converts solar energy into electrical energy. Usually, these systems are used separately.

However, it is worthy of note that PV systems are not able to exploit the whole spectrum of the terrestrial solar radiation $(0.25-2.5 \mu \mathrm{m})$ to generate electrical power. As a matter of fact, most of the solar cell materials, respond to a limited portion of the terrestrial solar spectrum. Therefore, only the radiations corresponding to the response range of the solar cell material are used by the solar cell to generate electricity. The unused radiations of the solar spectrum will dissipate their energy as heat inside the solar cell. This heat dissipation causes the thermal losses in the solar photovoltaic system, thereby reducing its performance. The output of the PV cells decreases when the operating temperature of the solar cell increases. Thus, in order to have a better performance, it is essential to maintain the low operating temperature of the solar cells (Skoplaki and Palyvos, 2009).

Therefore, in order to achieve higher electrical efficiency, the PV module should be cooled by removing the heat. This goal is achieved when the PV module is combined with a solar air/water heater collector. This type of system is called solar photovoltaic thermal (PV/T) collector. The PV/T collector produces thermal and electrical energy simultaneously. Besides the higher overall energy performance, the advantage of the PV/T system lies in the reduction of the demands on physical space and the equipment cost through the use of common frames and brackets as compared to the separated PV and solar thermal systems placed side-byside.

These features make PV/T systems suitable for building installations, where the problem of limited usable shadow-free space on building roof-tops could be overcome by the high overall electrical and thermal efficiency of a solar Photovoltaic Thermal (PV/T) system, which combines the electrical and thermal components in a single unit area. Consequently, PV/T collectors are currently considered as a valid contribute to the actual implementation of the nearly zero energy buildings" (NZEB) concept (Attia et al., 2017) (AbuGrain and Alibaba, 2017).

A significant amount of theoretical as well as experimental studies on the $\mathrm{PV} / \mathrm{T}$ systems has been carried out in the last 30 years (Chow, 2010; Joshi and Dhoble, 2018; Michael et al., 2015; Tyagi, Kaushik, and Tyagi, 2012).

As a contribute to this topic, the parametric analysis performed in this paper aims to provide indications about the influence of the storage system on the temperature of the working fluid and, therefore, on the performance of the system. These indications can be 
exploited by designers and researchers, to maximize the efficiency of the systems in relation to both electrical and thermal loads and to the features of the water thank.

Specifically, the proposed analysis is composed of a sequence of steps. Firstly, the system was outlined by singling out its components and, for each component, a mathematical model was developed to simulate the involved physical phenomena. Successively, the mathematical relations were implemented in a spreadsheet, using Visual Basic ${ }^{\mathrm{TM}}$ functions. Finally, the software was applied to assess the performance of the $\mathrm{PV} / \mathrm{T}$ system, by analysing each thermal and electric energy contribution.

Several configurations were analysed; collector area, dimension and insulation properties of the water tank and thermal load configuration were changed in order to examine the effect of the interaction of the system components on the thermal and electric energy generation and on the temperature of the working fluid, which is a crucial parameter with a view to meeting the requisites of the load.

\section{System Modelling}

The hybrid system was modelled considering two coupled components: a PV and a thermal collector. Therefore, the governing equations were elaborated considering the system depicted in Figure 1.

In correspondence of every calculation time step $\tau$, the PV collector, characterized by the efficiency $\eta_{P V}^{\tau}$, generates the power $\dot{Q}_{E}^{\tau}(\mathrm{W})$, whereas the thermal collector, characterized by the efficiency $\eta_{T}^{\tau}$, generates the thermal energy per unit of time $\dot{Q}_{T}^{\tau}(\mathrm{W}) \cdot \dot{Q}_{U}^{\tau}(\mathrm{W})$ is the global available thermal power, that is the power which is globally at the load disposal, $\dot{Q}_{u e}^{\tau}(\mathrm{W})$ is the effective thermal power, namely the thermal power which is actually sent to the thermal load $\dot{L} . \dot{Q}_{D}^{\tau}(\mathrm{W})$ is the thermal flow which is discarded into the environment through the envelope structure of the water storage. All the cited thermal flows and correspondent formulas are depicted in Figure 1.

The performance of the system was assessed under the hypothesis that, due to the effect of the interaction between absorber plate and PV cells panel, the actual cell temperature $t_{c, P V T}$ may be assumed equal to the average value:

$$
t_{c, P V T}^{\tau}=\frac{t_{c, P V}^{\tau}+t_{p}^{\tau}}{2}
$$

where $t_{c, P V}$ is the cell temperature which would characterize the performance of a standard PV system operating at the same condition of the actual PV/T plant.

The assumption was motivated by the following considerations. The possible values of the cell temperature of the $\mathrm{PV} / \mathrm{T}$ panel are restrained within a range whose limits are: $t_{c, P V}$ and $t_{p}$. For the higher inertia of the thermal component of the system (which exploits water as working fluid), it is more likely that the actual temperature of the cell, $t_{c, P V T}^{\tau}$, is nearer to the absorber temperature, $t_{p}$, than it is to cell temperature of the simple PV panel. Nonetheless, as a conservative hypothesis from the perspective of electric production, an average value was considered.

The cell temperature of the standard PV system operating at the same condition of the actual PV/T plant, $t_{c, P V}$, is usually calculated by means of the well known (Evans, 1981):

$$
t_{c, P V}^{\tau}=\left[t_{a}^{\tau}+\frac{N O C T-20}{800} I_{\beta}^{\tau}\right]
$$

where:

- NOCT is the Nominal Operating Cell Temperature $\left({ }^{\circ} \mathrm{C}\right)$;

- $\quad t_{a}^{\tau}$ is the air temperaure $\left({ }^{\circ} \mathrm{C}\right)$;

- $I_{\beta}^{\tau}$ is the solar irradiance on the panel surface $\left(\mathrm{W} / \mathrm{m}^{2}\right)$.

Therefore:

$$
t_{c, P V T}^{\tau}=0,5\left[t_{a}^{\tau}+\frac{N O C T-20}{800} I_{\beta}^{\tau}+t_{p}^{\tau}\right]
$$

where $t_{p}^{\tau}$ is the temperature of the absorber plate, assumed equal to:

$$
t_{p}^{\tau}=\frac{t_{F, i C}^{\tau}+t_{F, u C}^{\tau}}{2}
$$

where:

- $\quad t_{F, i C}^{\tau}$ e $t_{F, u C}^{\tau}$ are respectively the inlet and the outlet water temperature to the collector.

It was also assumed that:

- no fluid stratification occurs within the water tank, so that the storage temperature $t_{\mathrm{A}}$ is uniform (perfect mixing hypothesis), therefore $t_{F u, A}=t_{A}$, with $t_{F u, A}$ outlet water temperature of the water storage

- all the thermal loss within the water circuit are negligible, so that:

$$
\begin{array}{ll}
\text { - } & t_{F i, A}^{\tau}=t_{F, u C}^{\tau} \\
\text { - } & t_{F, i C}^{\tau}=t_{F u, A}^{\tau}
\end{array}
$$

where $t_{F i, A}^{\tau}$ is the inlet water temperature to the storage system; while $t_{F, i C}^{\tau}$ and $t_{F, u C}^{\tau}$ are, respectively, the inlet an outlet water temperature to the collector.

As regards the effective thermal power $\dot{Q}_{u e}^{\tau}$, namely the thermal power which is actually sent to the thermal load (L), it was calculated considering that, when the thermal energy production exceeds the thermal demand, only the needed portion of the global available thermal power $\dot{Q}_{U}$ (Figure 1) is used to meet the load $\dot{L}$ : 


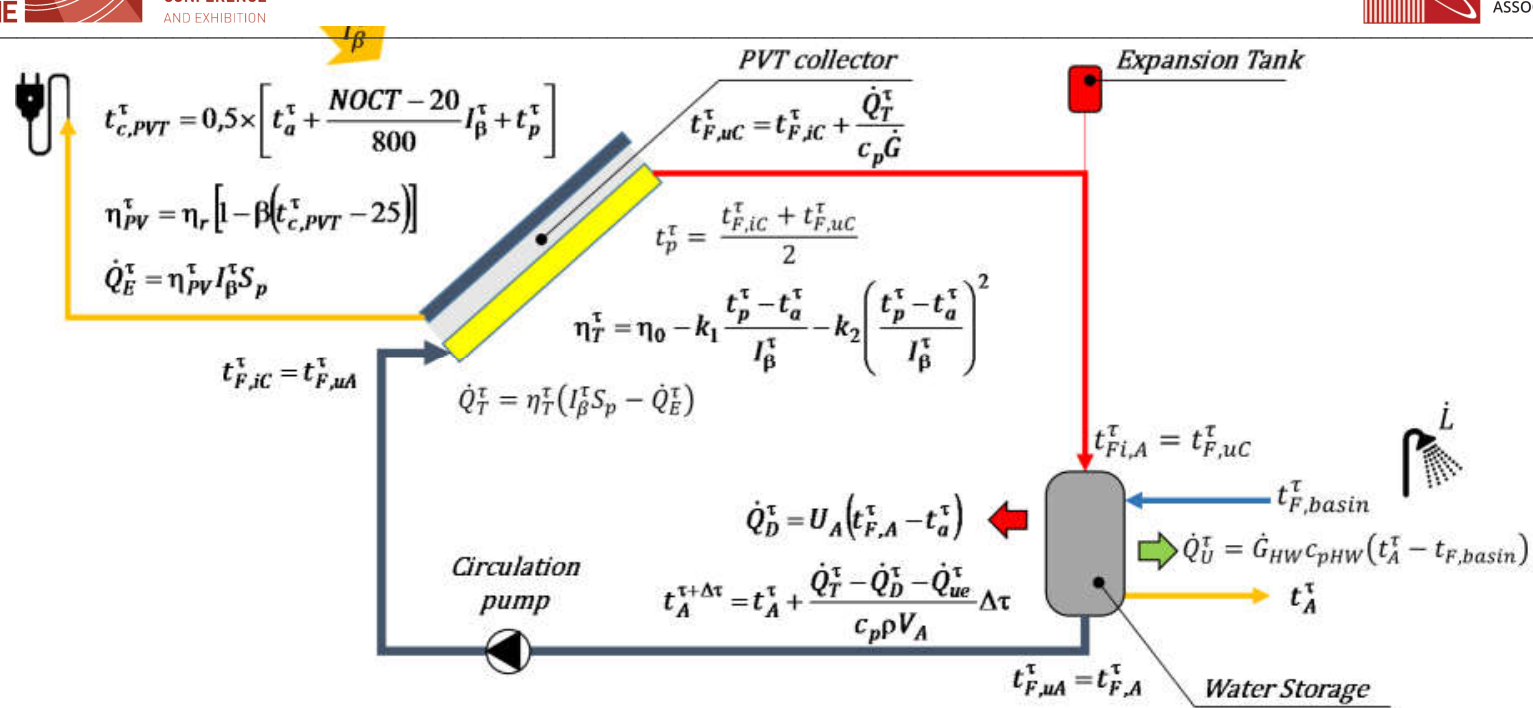

Figure 1. Scheme of the analysed system.

$$
\begin{array}{cccc}
\dot{Q}_{u e}^{\tau}=\dot{Q}_{U}^{\tau} & \text { if } & \dot{Q}_{U}^{\tau} \leq \dot{L}^{\tau} \\
\dot{Q}_{u e}^{\tau}=\dot{L} & \text { if } & \dot{Q}_{U}^{\tau}>\dot{L}^{\tau}
\end{array}
$$

Moreover, it was also assumed that

$$
\dot{Q}_{u e}^{\tau}=0 \quad \text { if } \quad \dot{Q}_{U}^{\tau}<0
$$

Finally, the electrical efficiency of the panel is:

$$
\eta_{P V, P V T}=\eta_{r}\left[1-\beta\left(t_{c, P V T}-25\right)\right]
$$

Whereas, the thermal efficiency of the panel is:

$$
\eta_{T, P V T}^{\tau}=\eta_{0}-k_{1}\left(\frac{t_{p}^{\tau}-t_{a}^{\tau}}{I_{\beta}^{\tau}}\right)-k_{2}\left(\frac{t_{p}^{\tau}-t_{a}^{\tau}}{I_{\beta}^{\tau}}\right)^{2}
$$

where:

- $\eta_{r}^{\tau}$, is the efficiency of the collector in correspondence of the reference temperature $\left(25^{\circ} \mathrm{C}\right)$;

- $\quad \beta$ is the temperature coefficient of the panel $\left[\%{ }^{\circ} \mathrm{C}^{-}\right.$ ${ }^{1}$ ];

- $\eta_{0}, k_{1}$ and $k_{2}$ are parameters characterizing the collector;

- $\quad t_{p}^{\tau}$ is the temperature of the absorber plate, assumed equal to: $t_{p}^{\tau}=\frac{t_{F, i C}^{\tau}+t_{F, u C}^{\tau}}{2}$.

The model was implemented in a spreadsheet, using Visual Basic ${ }^{\mathrm{TM}}$ function and macros, and a user-friendly interface was designed for the code.

The code output consists of:

- cell temperature $t_{c, P V T}^{\tau}$;

- inlet and outlet water temperature to the collector, $t_{F, i C}^{\tau}$ and $t_{F, u C}^{\tau}$;

- water storage temperature $t_{A}^{\tau}$;

- generated electrical power $\dot{Q}_{E}^{\tau}$;

- $\quad$ generated thermal energy $\dot{Q}_{T}^{\tau}$;

- global available thermal power $\dot{Q}_{U}^{\tau}$;

- effective thermal power $\dot{Q}_{u e}^{\tau}$;

- thermal flow through the envelope structure of the water storage $\dot{Q}_{D}^{\tau}$;

- $\quad$ electrical efficiency $\eta_{P V, P V T}^{\tau}$;

- thermal efficiency $\eta_{T, P V T}^{\tau}$.

\section{Perfor med Analys is}

In order to analyse the performance of the system, several configurations were patterned and simulated. They are summarized in Table 1, which reports the identification code (ID) of the case, the volume of the water storage $\left(\mathrm{V}_{\mathrm{s}}\right)$, the thermal transmittance of the tank envelope $\left(U_{s}\right)$, the load type and the area of the panel surface $\left(\mathrm{S}_{\mathrm{p}}\right)$.

Table 1. Analysed configurations.

\begin{tabular}{|c|c|c|c|c|}
\hline ID & $\begin{array}{c}\text { Vs } \\
\left(\mathrm{m}^{3}\right)\end{array}$ & $\begin{array}{c}\mathrm{Us} \\
\left(\mathrm{W} / \mathrm{m}^{2 \circ} \mathrm{C}\right)\end{array}$ & $\begin{array}{c}\text { Load } \\
\text { type }\end{array}$ & $\begin{array}{c}\mathrm{S}_{\mathrm{p}} \\
\left(\mathrm{m}^{2}\right)\end{array}$ \\
\hline S1-U05-L0-V025 & 0.25 & 0.50 & None & 1 \\
\hline S1-U05-L0-V025 & 10.0 & 0.50 & None & 1 \\
\hline S1-U05-LC-V025 & 0.25 & 0.50 & Constant & 1 \\
\hline S1-U05-LC-V10 & 10.00 & 0.50 & Constant & 1 \\
\hline S1-U05-LV-V025 & 0.25 & 0.50 & Variable & 1 \\
\hline S1-U05-LV-V10 & 10.00 & 0.50 & Variable & 1 \\
\hline S1-U5-L0-V025 & 0.25 & 5.00 & None & 1 \\
\hline S1-U5-L0-V025 & 10.0 & 5.00 & None & 1 \\
\hline S1-U5-LC-V025 & 0.25 & 5.00 & Constant & 1 \\
\hline S1-5-LC-V10 & 10.00 & 5.00 & Constant & 1 \\
\hline S1-U5-LV-V025 & 0.25 & 5.00 & Variable & 1 \\
\hline S1-U5-LV-V10 & 10.00 & 5.00 & Variable & 1 \\
\hline S5-U05-L0-V025 & 0.25 & 0.50 & None & 5 \\
\hline S5-U05-L0-V025 & 10.0 & 0.50 & None & 5 \\
\hline S5-U05-LC-V025 & 0.25 & 0.50 & Constant & 5 \\
\hline S5-U05-LC-V10 & 10.00 & 0.50 & Constant & 5 \\
\hline S5-U05-LV-V025 & 0.25 & 0.50 & Variable & 5 \\
\hline S1-U05-LV-V10 & 10.00 & 0.50 & Variable & 5 \\
\hline S5-U5-L0-V025 & 0.25 & 5.00 & None & 5 \\
\hline S5-U5-L0-V025 & 10.0 & 5.00 & None & 5 \\
\hline S1-U5-LC-V025 & 0.25 & 5.00 & Constant & 5 \\
\hline S5-5-LC-V10 & 10.00 & 5.00 & Constant & 5 \\
\hline S5-U5-LV-V025 & 0.25 & 5.00 & Variable & 5 \\
\hline S5-U5-LV-V10 & 10.00 & 5.00 & Variable & 5 \\
\hline & & & & \\
\hline
\end{tabular}

Climate Data

Climate data (solar radiation and air temperature - Figure 2) were measured at the Mediterranean University campus in Reggio Calabria (38 $5.7^{\prime}$ North Latitude; $15^{\circ} 39.3^{\prime}$ East longitude). 
Solar radiation was measured by means of a $\mathrm{CNR} 4^{\mathrm{TM}}$ net radiometer (Kipp and Zonen), which, in turn, consists of a pyranometer pair, disposed on the opposite surfaces of the probe's plane, and a pyrgeometer pair in a similar configuration.

Air temperature was measured by means of the Vaisala WXT 530 weather station.

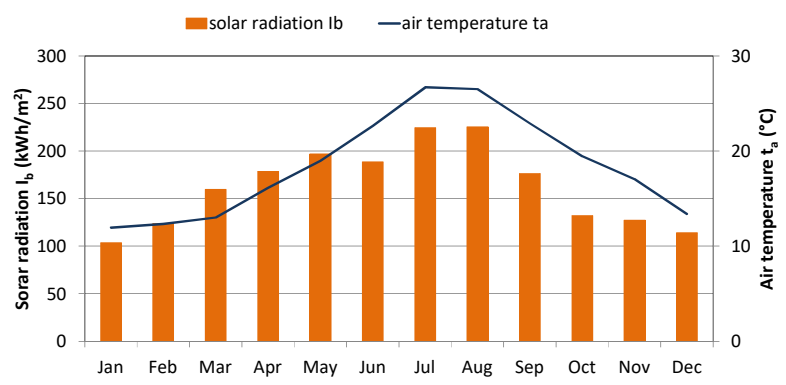

Figure 2. Monthly horizontal solar ra diation and monthly average air temperatu re

Thermal load

The analysed thermal load consists in the energy demand for Domestic Hot Water (DHW) for a flat of about 100 $\mathrm{m}^{2}$. It was assessed by means of the procedure reported in the UNI/TS 11300-2 Standard (Ente Nazionale Italiano di Unificazione, 2014).

Two load configurations were considered: variable and constant.

In the variable configuration the daily load, calculated by means of the UNI/TS 11300-2 Standard procedure, was spread along the hours of the day according to the end user profile, as reported in Figure 3, which refers to the ratio between the hourly load and the daily load. It was elaborated following the indication reported in (AICARR, 2005).

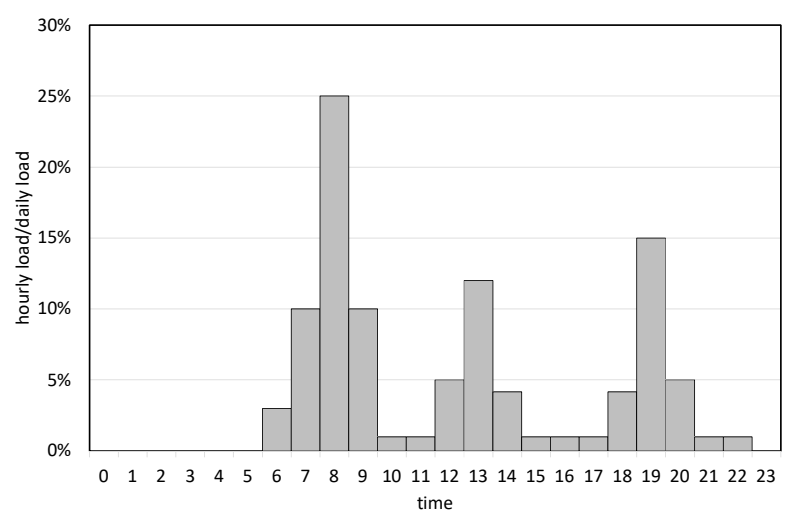

Figure 3 - Hourly distribution of the daily thermal load.

Successively, such load was statistically treated to obtain a daily variant DHW demand. Specifically, an hourly noise was added to make the load data more realistic: each day's load profile was perturbed by a random amount, so that the load retains the same size, but is scaled upwards or downwards.

The resulted time trend of the daily load is reported in Figure 4.
In the constant configuration the annual load was constantly allotted to each hour according to the formula:

$$
L C_{h}=\frac{\sum_{i=1}^{8760} L V_{i}}{8760}
$$

where $L C_{h}$ is the constant hourly thermal load, $L V_{i}$ is the variable hourly thermal load at time $\mathrm{i}$.

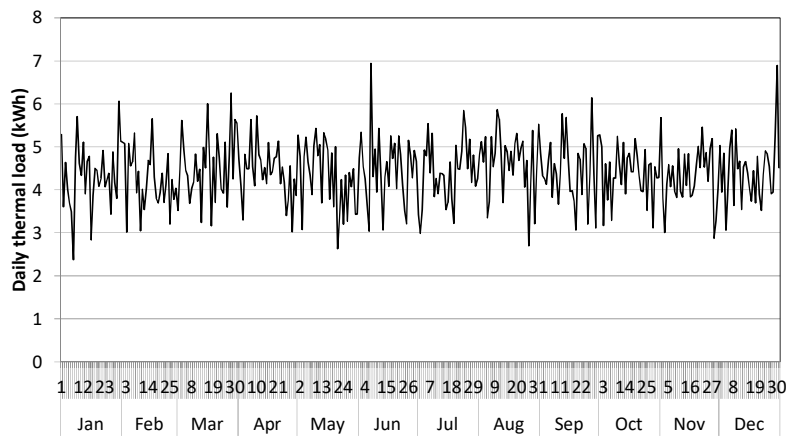

Figure 4 -Daily thermal load.

$\mathrm{PV} / \mathrm{T}$ collector feature $\mathrm{s}$

The characteristics of the analysed system are reported in Table 2.

Table 2. Characteristics of the analysed panel.

\begin{tabular}{|c|c|}
\hline \multicolumn{2}{|c|}{ PV panel features } \\
\hline Peak power $(\mathrm{W})$ & 170 \\
\hline$\eta_{r}$ & 0.15 \\
\hline NOCT $\left({ }^{\circ} \mathrm{C}\right)$ & 45.0 \\
\hline$\beta\left[\%{ }^{\circ} \mathrm{C}^{-1}\right]$ & -0.4 \\
\hline \multicolumn{2}{|c|}{ Thermal feature $\mathrm{s}$} \\
\hline$\eta_{0}$ & 0.500 \\
\hline$k_{1}\left(\mathrm{~W} \mathrm{~m}^{-1} \mathrm{~K}^{-1}\right)$ & 4.58 \\
\hline$k_{2}\left(\mathrm{~W}^{2} \mathrm{~m}^{-2} \mathrm{~K}^{-2}\right)$ & 0.00135 \\
\hline
\end{tabular}

\section{Results}

Figure 5 and Figure 6 report the annual energy production of the configurations corresponding to the configurations in which $S_{p}=5 \mathrm{~m}^{2}$ was considered.

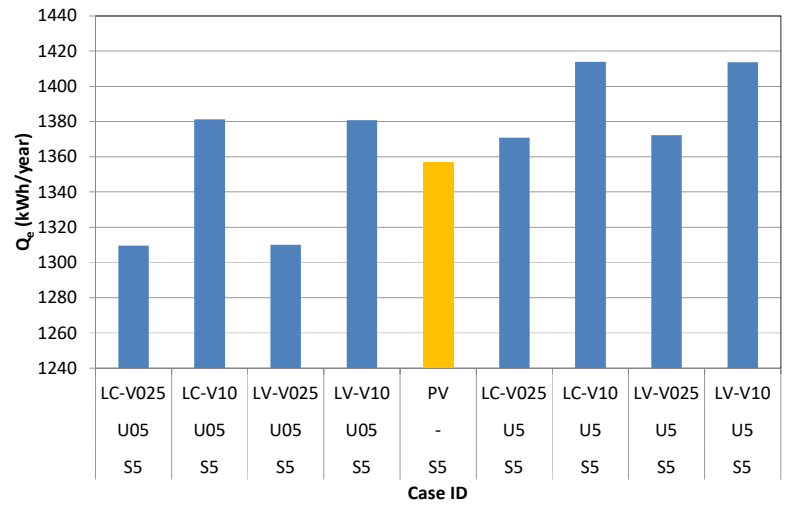

Figure 5 - Annual electrical energy production

$$
\left(S_{p}=5 \mathrm{~m}^{2}\right) \text {. }
$$

Specifically, Figure 5, where the standard PV system (PV-S5) is used as a reference (yellow bar), refers to the electric energy $Q_{e}$, whereas Figure 6 refers to the global available thermal energy $Q_{U}$. 


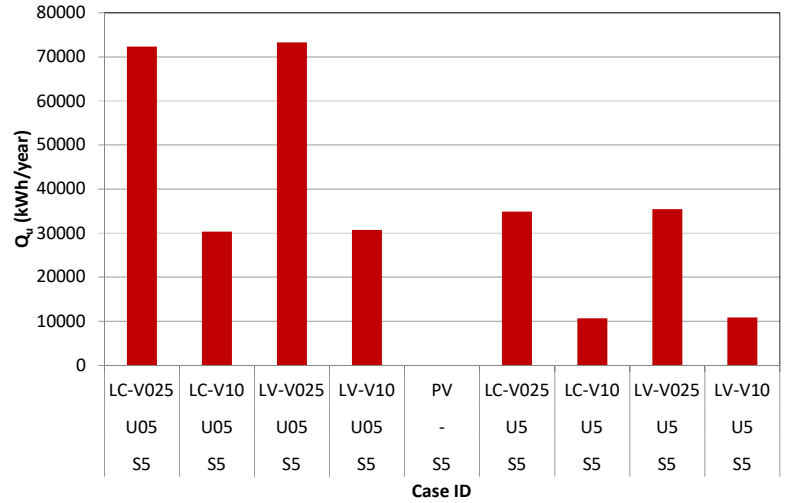

Figure 6 - Annual thermal energy production

$$
\left(S_{p}=5 \mathrm{~m}^{2}\right) \text {. }
$$

It is worthy of note that the load configuration (constant or variable) feebly influences both energy productions which are more strongly affected by the storage volume and the insulation properties of the tank.

On balance, as expected, larger tanks with higher thermal transmittance values are to be preferred if electrical energy production is the main goal of the system.

As a matter of fact, both these conditions contribute in reducing the cell temperature, thus enhancing the efficiency of the PV system.

This conclusion may be inferred by the data reported in Figure 7 and Figure 8, which depict, as an example, the time trend of the cell temperature during the first six days of the months of June and December.

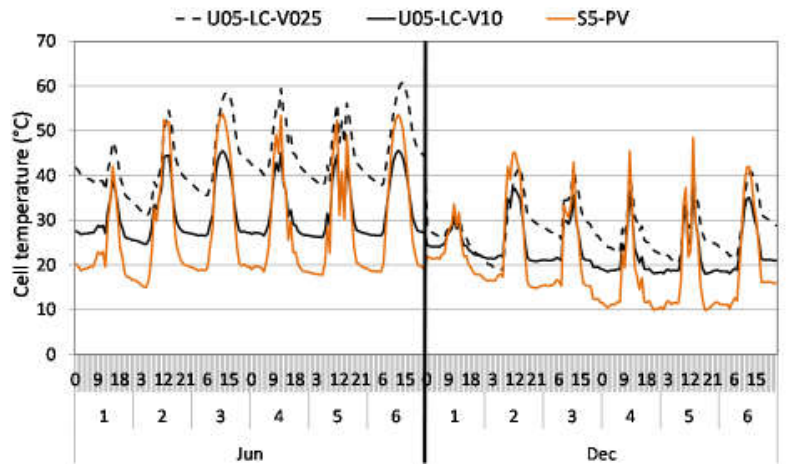

Figure 7 - Cell temperature trend

$$
\left(S_{p}=5 \mathrm{~m}^{2} ; U_{S}=0.5 \mathrm{Wm}^{-2} \mathrm{~K}^{-1}\right) \text {. }
$$

On the other hand, larger and less insulated tanks reduce the amount of available thermal energy produced annually (Figure 6). Nevertheless, it may be always used to pre-heat the water that must be delivered to the load.

From this perspective the temperature of the water storage plays a pivotal role. In fact, regardless of the global amount of thermal energy annually available, it is the temperature at which this energy is provided that influences the system capacity to meet the load.

The time trend of the water storage temperature is depicted in Figure 9 and Figure 10 for the first six days of both June and December. Reported data refer to the $S_{p}=5 \mathrm{~m}^{2}$ configuration. For comparison purposes, both constant load (LC) and no-load (L0) configurations were reported.

It can be noted that for the highest storage volume, the water temperature is not always suited to comply with the requisites of the load which needs water at a temperature of $37^{\circ} \mathrm{C}$ at least.

Therefore, in this case the water storage can be exploited to pre-heat the water, supporting the auxiliary heating source.

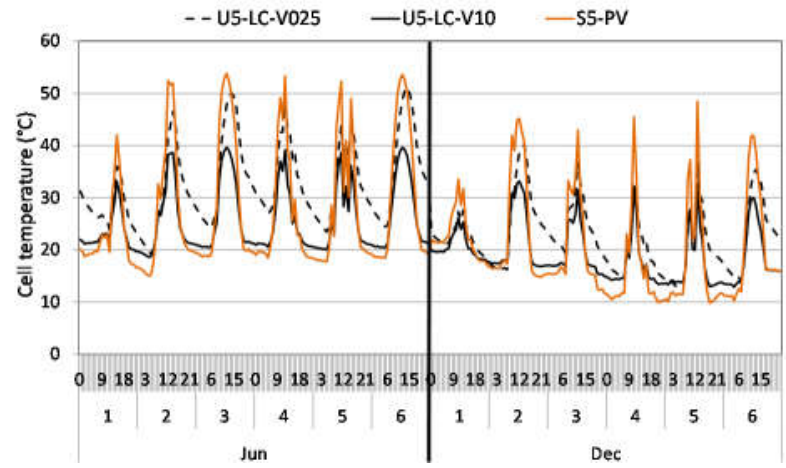

Figure 8 - Cell temperature trend $\left(S_{p}=5 \mathrm{~m}^{2} ; U_{S}=5 \mathrm{Wm}^{-2} \mathrm{~K}^{-1}\right)$.

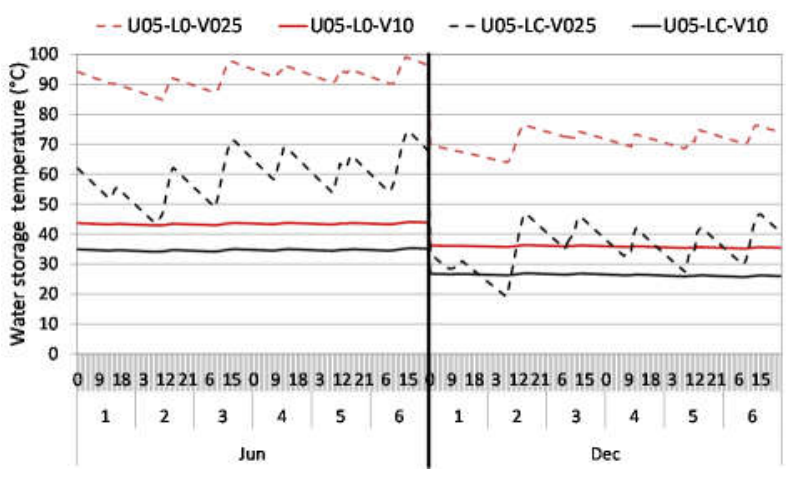

Figure 9 - Water Stora ge temperatu re $\left(S_{p}=5 \mathrm{~m}^{2} ; U_{S}=0.5 \mathrm{Wm}^{-2} \mathrm{~K}^{-1}\right)$

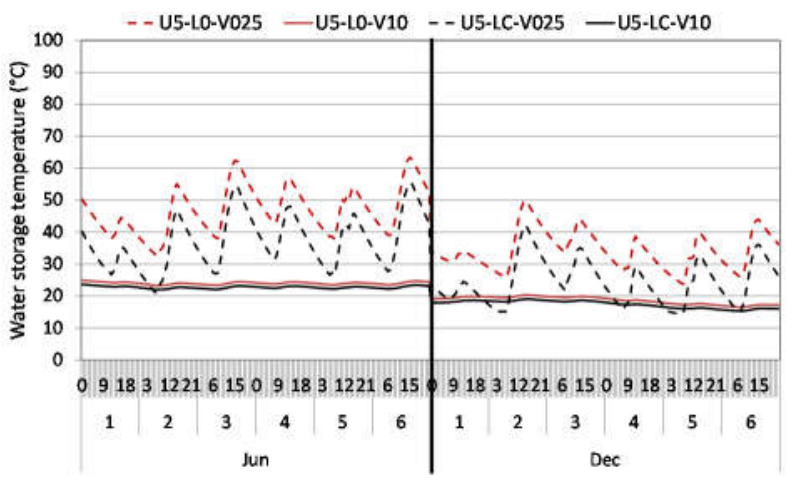

Figure 10 - Water Stora ge temperatu re $\left(S_{p}=5 \mathrm{~m}^{2} ; U_{S}=5.0 \mathrm{Wm}^{-2} \mathrm{~K}^{-1}\right)$

Annual energy production for the $S_{p}=1 \mathrm{~m}^{2}$ configurations are reported in Figure 11 and Figure 12.

In this case, on average, the electrical production of the $\mathrm{PV} / \mathrm{T}$ system is always about $5 \%$ higher than the one provided by the standard PV. The storage configuration seems to have a slender influence on this behaviour, also 
demonstrated by the cell temperature time trend (Figure 13 and Figure 14).

As far as the annual thermal energy production is concerned, it may be noted how it rises with the storage volume.

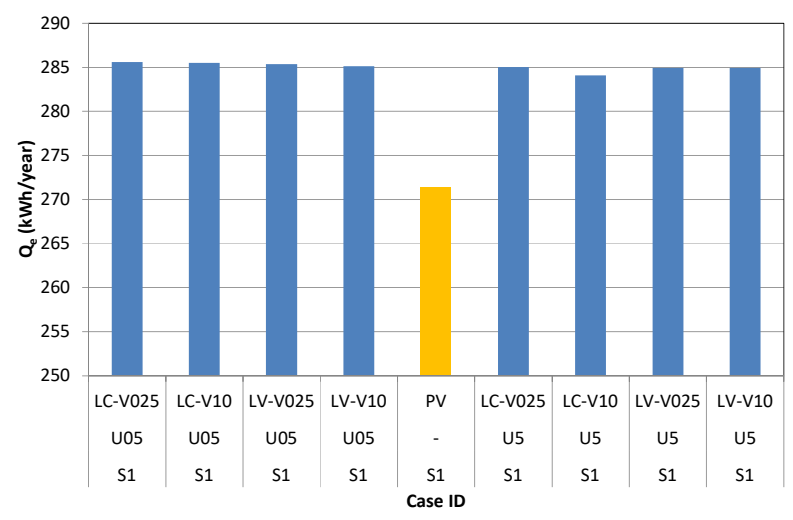

Figure 11 - Annual electrical energy production $\left(S_{p}=1 \mathrm{~m}^{2}\right)$.

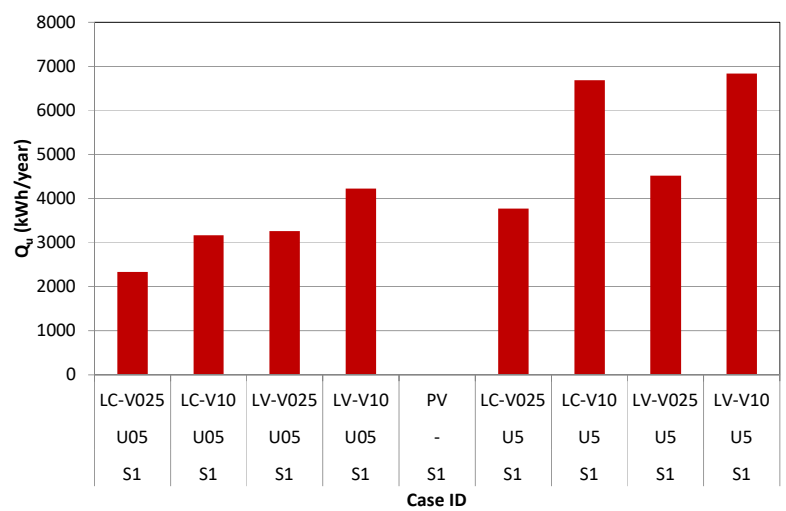

Figure 12 - Annual thermal energy production

$$
\left(S_{p}=1 \mathrm{~m}^{2}\right) \text {. }
$$

The contribute of the thermal flows through the tank envelope play a pivotal role within this context. As a matter of fact, during spring and summer periods these flows heat up the water storage, so that if both the dimension and the thermal transmittance of the tank envelope are increased, the water undergoes an additional heating that is able to compensate the reduced production from the panel.

Figure 15, which depicts, as an example, the time trend of the thermal flows through the tank envelope during three days of August for the two analysed thermal transmittance configurations and $\mathrm{V}=10 \mathrm{~m}^{3}$, makes this phenomenon even more evident.

However, as regard to the water temperature, it may be concluded that, on average, it is not suited to comply with the requisites of the load which needs water at a temperature of $37^{\circ} \mathrm{C}$ at least. This conclusion can be drawn from the analysis of the data reported in Figure 16, which depicts the water storage daily average temperature for two configurations of the tank insulation properties

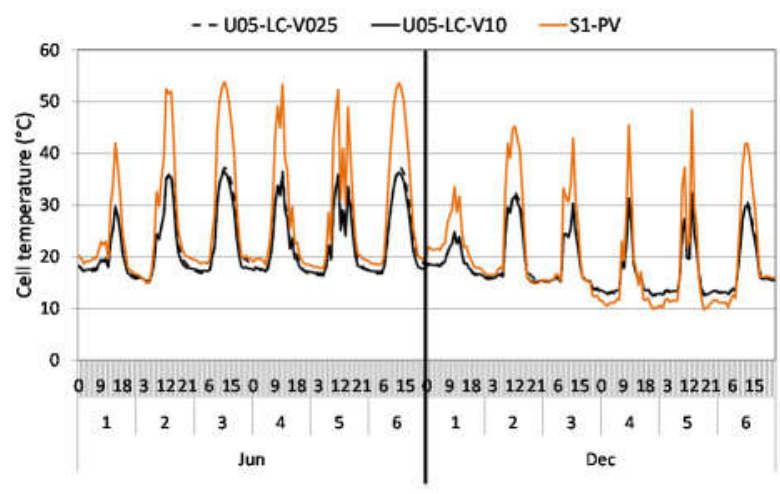

Figure 13 - Cell temperature trend $\left(S_{p}=1 \mathrm{~m}^{2} ; U_{S}=0.5 \mathrm{Wm}^{-2} \mathrm{~K}^{-1}\right)$.

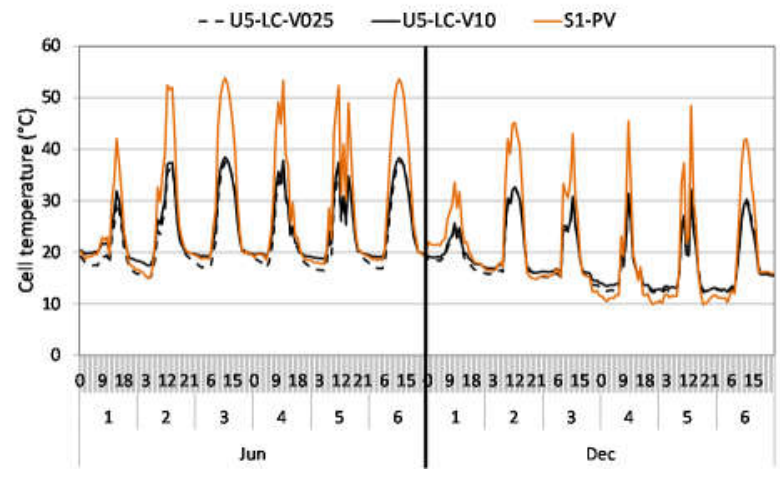

Figure $14-$ Cell temperatu re trend $\left(S_{p}=1 \mathrm{~m}^{2} ; U_{S}=5.0 \mathrm{Wm}^{-2} \mathrm{~K}^{-1}\right)$.

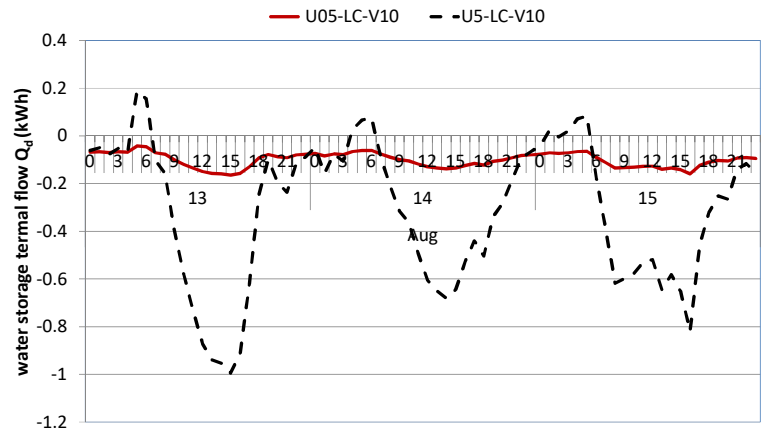

Figure 15 - Thermal flows through the tank envelope

$$
\left(S_{p}=1 \mathrm{~m}^{2}\right) \text {. }
$$

Therefore, the water storage can be exploited to pre-heat the water, thus supporting auxiliary heating source.

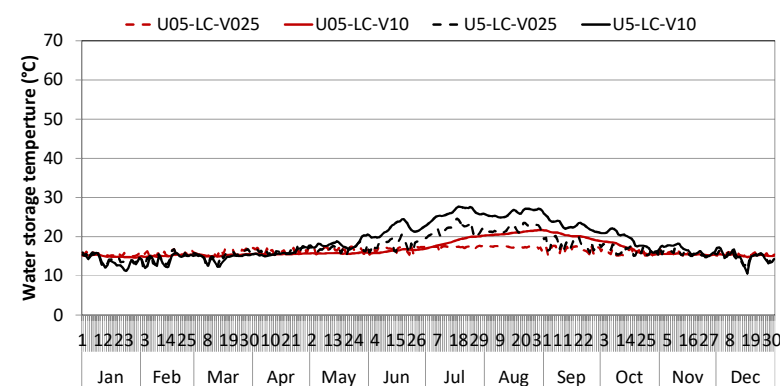

Figure 16 - Water Stora ge daily average temperatu re

$$
\left(S_{p}=1 \mathrm{~m}^{2}\right) \text {. }
$$




\section{Conclus ion}

The paper illustrates the results of a parametric analysis which aims to provide indications about the influence of the system configuration on the temperature of the working fluid and, therefore, on the performance of PVT systems. These indications can be exploited by designers and researchers, to maximize the efficiency of the systems in relation to both electrical and thermal loads and to the features of the water storage.

In order to simulate the system performances a specific code was elaborated and implemented in a spreadsheet, using Visual Basic ${ }^{\mathrm{TM}}$ function and macros.

Results seem to demonstrate that, from the perspective of the yearly electrical energy production:

- the water storage configuration plays a pivotal role when the largest collector surfaces are involved; in this case, the water storage configuration is crucial to dissipate the heat from the PV cells and to improve the collector efficiency;

- the water storage influence is negligible for the system configuration which involves the smallest collector area; in this case, the excess heat is removed efficiently from the PV cells regardless the water storage dimension or insulation properties of the tank.

As far as the thermal production is concerned, it can be stated that:

- both the smallest collector area configuration and the largest one allowed the PVT system to act as a pre-heating device supporting the auxiliary heating source;

- the most efficient configuration demonstrated to be the one with the largest collector area and the smallest and most insulated storage which allowed the highest water temperature to be reached, especially during spring-summer seasons;

- in the case of the smallest collector area configuration, the highest thermal production was obtained with the largest and less insulated water tank; this configuration, as a matter of fact, made the heat flow through the tank envelope rise; owing to both the mild outdoor air temperature characterizing the site, the phenomenon caused the intensification of the heat gains through the tank envelope which acted balancing the limited production of the small thermal collector, thus raising the water temperature.

In conclusion, the selection of the best configuration depends on the purpose that is to be fulfilled.

When the electrical load has priority over the thermal one, larger collector area may call for larger and less insulated water tank both to enhance the cooling effect and to improve the system performance; but this does not happen when smaller collector surfaces are involved: in this case the water storage configuration demonstrated a negligible influence on the electrical power generation. On the contrary, when thermal load has priority over the electrical one, heat production needs to be maximized.
The water storage configuration which allows this objective to be reached depends on the collector size. For the considered climate conditions, the reduced heat production from small collector area may be improved with larger and less insulated water storage tanks. Conversely, when large collector areas are involved, the heat production rises when smaller and more insulated water storage tanks are installed.

In this case, the limit to the reduction of the water storage size is determined by the necessity of not compromising the needed cooling effect of the PV cells and the consequent electrical power production.

\section{Nomenclature}

G water flow $(\mathrm{kg} / \mathrm{s})$.

$I_{\beta} \quad$ solar irradiance on the panel surface $\left(\mathrm{W} / \mathrm{m}^{2}\right)$;

$k_{1}, k_{2}$ parameters characterizing the collector (nondimens.);

$\dot{L}^{\tau} \quad$ thermal load (W);

NOCT Nominal Operating Cell Temperature $\left({ }^{\circ} \mathrm{C}\right)$;

$\dot{Q}_{D}^{\tau} \quad$ thermal flow which is discarded into the environment through the envelope structure of the water storage $(\mathrm{W})$;

$\dot{Q}_{E}^{\tau} \quad$ generated electrical power (W);

$\dot{Q}_{T}^{\tau} \quad$ generated thermal power (W);

$\dot{Q}_{U}^{\tau} \quad$ global available thermal power, namely the power which is globally at the load disposal (W);

$\dot{Q}_{u e}^{\tau} \quad$ effective thermal power, namely the thermal power which is actually sent to the thermal load (W);

$\mathrm{S}_{\mathrm{p}} \quad$ area of the panel surface $\left(\mathrm{m}^{2}\right)$;

$t_{a} \quad$ air temperaure $\left({ }^{\circ} \mathrm{C}\right)$;

$\mathrm{t}_{\mathrm{A}} \quad$ storage temperature $\left({ }^{\circ} \mathrm{C}\right)$;

$t_{c, P V} \quad$ cell temperature e of a standard PV system operating at the same condition of the actual $\mathrm{PV} / \mathrm{T}$ plant $\left({ }^{\circ} \mathrm{C}\right)$;

$t_{c, P V T}$ actual cell temperature of the $\mathrm{PV} / \mathrm{T}$ collector $\left({ }^{\circ} \mathrm{C}\right)$;

$t_{F i, A} \quad$ inlet water temperature to the storage system $\left({ }^{\circ} \mathrm{C}\right)$;

$t_{F u, A}$ outlet water temperature of the water storage $\left({ }^{\circ} \mathrm{C}\right)$;

$t_{F, i C} \quad$ inlet water temperature to the collector $\left({ }^{\circ} \mathrm{C}\right)$;

$t_{F, u c} \quad$ outlet water temperature to the collector $\left({ }^{\circ} \mathrm{C}\right)$;

$\mathrm{t}_{\mathrm{p}} \quad$ temperature of the absorber plate $\left({ }^{\circ} \mathrm{C}\right)$;

Greek Symbols

$\beta \quad$ temperature coefficient of the panel $\left(\%{ }^{\circ} \mathrm{C}^{-1}\right)$;

$\eta_{0} \quad$ parameter characterizing the collector (nondimens.); 
$\eta_{P V, P V T}$ electrical efficiency (non-dimens.);

$\eta_{r} \quad$ efficiency of the thermal collector in correspondence of the reference temperature $\left({ }^{\circ} \mathrm{C}\right)$;

$\eta_{T, P V T}$ thermal efficiency (non-dimens.).

\section{Ackn owledgement}

This work was carried out within the research project $n$. 201594LT3F, "La ricerca per i PAES: una piatta forma per le municipalità partecipanti al Patto dei Sindaci (Research for SEAP: a platform for municipalities taking part in the Covenant of Mayors)", which is funded by the PRIN (Programmi di Ricerca Scientifica di Rilevante Interesse Nazionale) of the Italian Ministry of Education, University and Research.

\section{References}

AbuGrain, Mohammad Y., and Halil Z. Alibaba (2017). Optimizing Existing Multistory Building Designs towards Net-Zero Energy. Sustainability (Switzerland) 9 (3). doi:10.3390/su9030399.

AICARR (2005). Manuale d'ausilio alla progettazione termotecnica, Associazione Italiana Condizionamento dell'Aria, Riscaldamento e Refrigerazione, Milano, Italy (in italian).

Attia, Shady, Polyvios Eleftheriou, Flouris Xeni, Rodolphe Morlot, Christophe Ménézo, Vasilis Kostopoulos, Maria Betsi, et al. (2017). Overview and Future Challenges of Nearly Zero Energy Buildings (NZEB) Design in Southern Europe. Energy and Buildings 155 (November). Elsevier: 439-58. doi:10.1016/j.enbuild.2017.09.043.

Chow, T. T. (2010). A Review on Photovoltaic/Thermal Hybrid Solar Technology. Applied Energy 87 (2). Elsevier Ltd: 365-79. doi:10.1016/j.apenergy.2009.06.037.

Duffie, J.A. and W.A. Beckman (2013). Solar Engineering of Thermal Processes, John Wiley \& Sons, Inc.

Ente Nazionale Italiano di Unificazione, UNI (2014).
Energy Performance of Buildings Part 2: Evaluation of Primary Energy Need and of System Efficiencies for Space Heating, Domestic Hot Water Production, Ventilation and Lighting for Non-Residential Buildings. Italy.

Evans, DL. (1981). Simplified Method for Predicting PV Array Output. Sol Ar Energy 27 (6): 555-60. doi:https://doi.org/10.1016/0038-092X(81)900517 Get.

International Energy Agency (IEA) (2018). Solar PV. https://www.iea.org/tcep/power/renewables/solar/.

Joshi, Sandeep S., and Ashwinkumar S. Dhoble (2018). Photovoltaic - Thermal Systems (PVT): Technology Review and Future Trends. Renewable and Sustainable Energy Reviews 92 (April). Elsevier Ltd: 848-82. doi:10.1016/j.rser.2018.04.067.

Michael, Jee Joe, Iniyan S, and Ranko Goic (2015). Flat Plate Solar Photovoltaic-Thermal (PV/T) Systems: A Reference Guide. Renewable and Sustainable Energy Reviews 51. Elsevier: 62-88. doi:10.1016/j.rser.2015.06.022.

Panwar, N.L., S.C. Kaushik, and S. Kothari (2011). Role of Renewable Energy Sources in Environmental Protection: A Review. Renewable and Sustainable Energy Reviews 15 (3). Elsevier Ltd: 1513-24. doi:10.1016/j.rser.2010.11.037.

Skoplaki, E., and J. A. Palyvos (2009). On the Temperature Dependence of Photovoltaic Module Electrical Performance: A Review of Efficiency/Power Correlations. Solar Energy 83 (5): 614-24. doi:https://doi.org/10.1016/j.solener.2008.10.008.

Tyagi, V. V., S. C. Kaushik, and S. K. Tyagi (2012). Advancement in Solar Photovoltaic/Thermal (PV/T) Hybrid Collector Technology. Renewable and Sustainable Energy Reviews 16 (3). Elsevier Ltd: 1383-98. doi:10.1016/j.rser.2011.12.013. 